\title{
Energy Healing through Some Esoteric Yogic Practices
}

\author{
Anand I* \\ Specializing as a Trained Yoga Teacher, and a Reiki \& Pranic Healing Practitioner, UK \\ ${ }^{*}$ Corresponding author: Dr Indira Anand, (Ayurvedic Studies) Specializing as a \\ Trained Yoga Teacher, and a Reiki \& Pranic Healing Practitioner, 18 West End \\ Mini Review \\ Volume 2 Issue 7 \\ Received Date: September 11, 2018 \\ Published Date: September 28, 2018 \\ DOI: $10.23880 /$ jonam- 16000154
}

Avenue, Pinner, Middlesex, HA5 1BJ, UK, Tel: 0208429 0635; 07801325 198; Email: ianand@talktalk.net

\begin{abstract}
Traditional Medicine and Alternative healthcare represent more than just two different approaches to healing disease. They illustrate two essentially different paradigms of reality. The former developed with serious regard to scientific terminology embraces the premise that it is the physical world that contains the forces which exert the strongest influences on the body. Thus it works from outside-in. The fundamental principle of Holistic philosophy is that illness results when mental, emotional or psychological stresses become overwhelming and thus cause a weakening of the body making it susceptible to disease. In other words the energy level of the individual precedes and determines all that is experienced at the physical level of life. The two camps seem to be opposed to and quite critical of each other. In reality, they are meant to complement each other and become integrated.
\end{abstract}

\section{Introduction}

The experience, knowledge and technologies of both Traditional and Alternative healthcare are valid, substantial and potent. Analyzing critically, all healing will be found to be scientific. What we need is integration. If any field needs an integrative paradigm that can make sense out of all the different modes of healing, it is medicine.

The weaknesses of the conventional medical model have been clear for some time. There is no conventional medical model for the treatment of most chronic and degenerative diseases. At the same time, there is much anomalous data on spontaneous healing; the overnight cure of cancer without any medicine is an example of spontaneous healing, which the materialist paradigm of medicine cannot explain. On the other hand there is a resurgence of interest in ancient alternative healing practices. Why?
Clearly, a paradigm shift is needed. We need to eliminate the need for any medicinal modality to claim that it is the only true way. We are just beginning to explore areas of mind-body interactions and measure what emotional states such as depression or love do to the body. If the human body is understood in terms of the human energy system, our emotional anatomy will be found to be as real as our physical anatomy. The health of the psyche and spirit are manifested on a cellular level as physical health or disease. In no place is the interaction among mind, body and biochemistry more obvious than it is in psychological and mental disorders. And in no area of modern medicine is there greater controversy than in the whole field of emotional illnesses.

The challenge to physicians is that of accepting emotional disorders as 'real'. Perhaps only when this is fully accepted by physicians will we recognise that you cannot cure emotions with drugs and surgery. You can anesthetize, you can suppress or repress emotions with 


\section{Journal of Natural \& Ayurvedic Medicine}

drugs and surgery but you cannot cure the basic disorder. Of equal importance is the fact that there is an emotional component, either as a precipitating or as an aggravating factor in every psychological or mental disorder. It is only recently that science has been able to tune into the universal energy via its advances in technology. We are also learning to discover more and more about the subtle levels of the energy or 'prana' that surround us, yet are beyond our sensory capacity. Pranic healers possess the ability to perceive prana at a subtle level and to manipulate it for healing.

There is no doubt that people have started to appreciate the ancient tools that exist for connecting mind and body like Ashtanga Yoga which includes Meditation. The less well-known but more potent practices, which were kept secret by the ancient yogis to avoid being misused, like Yoga Nidra, Prana Nidra, Swara Yoga, Tattwa Shuddhi, Prana Vidya, Kriya Yoga etc., could have a dramatic effect on the energy body and over-all health of the individual - all free of cost. A relearning of what our ancestors already knew about the techniques of healing is now required. This article will focus on some of these esoteric Yogic practices as a means of energy healing [1$3]$.

\section{Rationale of Energy Healing}

The two basic principles of the universe are Energy \& Consciousness. At the level of the individual, prana is the vital energy flowing within the body to keep every organ alive and active. This individual life force is a part of the universal prana or energy just as individual consciousness is a part of universal consciousness. They are opposite poles of the same principle. Changes in the level of prana can be brought about by changes in the state of consciousness and vice versa.

The physical body is a storehouse of pranic energy. Each fibre of the body is connected with prana by a complex system of energy channels. The six major chakras or energy vortices are located where numerous energy channels converge. Each chakra governs and distributes energy to a particular region of the body. Energy is distributed to each and every organ and cell of the body through innumerable energy channels emanating from the chakras. Thus the functioning of the physical body is directly related to the quality and quantum of energy flowing within the pranic body.

When the flow is increased it can be directed to the weaker or diseased parts of the body for repair and healing. Whether this flow is increased by access to cosmic energy or by working directly on the dormant energy in the body is another matter. The direction of energy is done in different ways in different systems of healing. But intentionality is an important ingredient. When intentionality is combined with visualisation, faith and belief, we also access the valuable assistance of the powerful subconscious mind in delivering results [4-6].

The works of Dr Hiroshi Motoyama, Dr Hunt, Dr Koji Tsuchiya and others have contributed significantly in providing scientific evidence to the existence of chakras and energy channels using especially developed 'Chakra Machine' and AMI instrument (Apparatus for Meridian Identification), which is currently in use in some American and many Japanese medical institutions as both a diagnostic tool and for research into health and disease [6].

\section{Yogic \& Tantric Practices}

Yoga Nidra, Prana Nidra, Swara Yoga, Tattwa Shuddhi, Prana Vidya etc are potent practices which can aid healing at all levels. Let me start with the simplest and move on to more advanced practices

\section{Yoga Nidra-The Blissful Relaxation}

Yoga Nidra is the simplest and the most effective way to relieve physical, emotional and mental tensions. Nidra means sleep. Most people sleep without resolving their tensions but yoga nidra means sleep after throwing off the burdens. It is a blissful relaxation. Most psychosomatic diseases arise from tensions in the body and mind that block the flow of energy, which modern medical science is ill-equipped to tackle. In the state of yoga nidra the subconscious mind is tapped and previously suppressed material is permitted to rise spontaneously into awareness by using specific images and archetypes designed to liberate this subconscious material. Selfrecognition and desensitisation to painful memories follow spontaneously, restoring psychosomatic balance. Thus one learns to relax not just the physical body, but the pranic body, the emotions, the mind and the psyche. The released energy is redirected for healing and rejuvenation of overtaxed tissues, glands and organs [79].

Yoga Nidra has widespread application in the management of diseases of all kinds and promises to play a far greater role in the future as its potential becomes fully recognised by doctors, psychologists and healers. Its 


\section{Journal of Natural \& Ayurvedic Medicine}

value as both a curative and a palliative has been investigated in recent years in many research centres around the world, with extremely favourable results. It has been found useful in both acute and chronic conditions, especially in degenerative and stress related conditions such as hypertension, coronary disease and arthritis. Diseases with a high psychosomatic component such as asthma, peptic ulcers and migraine headache respond favourably to yoga nidra therapy. It has also proved successful in treating insomnia, drug addiction and alcoholism [8].

The practice of yoga nidra throughout pregnancy helps to create the most favourable conditions for intrauterine growth and development. Yoga nidra has its most widespread application as a preventive measure to be practised by healthy, active people as a means of relieving accumulated tensions and preventing psycho-somatic diseases. It is easy to practise by following pre-recorded instructions and can be made more potent by using a 'healing resolve'.

\section{Pran Nidra}

In Prana Nidra, a technique similar to yoga nidra, the awareness is systematically directed to various levels and experiences of prana. In both yoga nidra and prana nidra, one experiences, at increasingly subtle levels, things about oneself of which one was previously not aware. One develops pranic sensitivity and harmonizes the pranas. Both these aspects are essential for success in higher practices. One relaxes the physical body, the mental body, one awakens the intuitive sheath of knowledge and the inner awareness of bliss, by encouraging deeper and deeper states of relaxation while maintaining the awareness of a witness. The aim of the practice is to expand the awareness and the experience of prana or vital energy force, in previously unconscious areas and bring the experience of the energy body to our conscious awareness.

It deals with four main types of experiences:

- The flow of energy in the five types of prana

- The flow of energy in the energy channels

- The flow of energy in the chakras, and

- The expression of these energy flows, particularly at the levels of vitality, feelings and emotions.

It is useful as a physical therapy, as a mental therapy and also useful in changing one's perspectives and lifestyle. Like Yoga Nidra, it is easy to practise by following pre-recorded instructions [8].

\section{Swar Yoga}

The literal translation of swara is the sound of one's own breath. Swara is the flow of prana, through the nostrils- a very subtle and vital aspect of the breath. Swara Yoga is a complete science with enormous applications. I can only scratch the surface in this article and deal with its everyday use in healthcare.

Approximately every hour the active nostril changes. This rhythm regulates all the psychological and physiological processes in the body. In the human body the three swaras (through the left, right and both nostrils) correspond to the three major systems-Mind-Chitta, life force - prana and soul-atma. Mind controls the sensory nerves, prana controls the five organs of action and atma or the soul is the overall controller. In its simplest form, attention to right or left nostril breathing could help so many health conditions. Patients suffering from kapha diseases like obesity, edema, muscle stiffness and paralysis should focus on right nostril breathing which works on the left side of the brain and controls physical activity. Right nostril breathing also helps to overcome sleepiness, dullness and fatigue. Patients suffering from diseases of heat like fevers, wasting diseases, ulcers, paralysis, loss of body weight etc should emphasise left nostril breathing which is cooling and calming, stimulates the right side of the brain and controls mental activity. By balancing the right and left nostril breathing through pranayama and other techniques, one can optimise one's productivity. Thus, using the right swara, by over-riding the natural rhythm, can prove helpful in many other ways.

\section{Tattwa Shuddhi (Purification of Elements) for general Self -Healing}

In Ayurveda, we use panchakarma to get rid of the toxins in the physical body. But Tattwa shuddhi is purification of one's gross, subtle and psychic elements. Hence it should not only be conceived as physical purity but also beyond the gross body, purification of the several other bodies or planes of existence related to the hidden layers of the mind. It is considered an essential step towards higher spiritual experience. However, it can also be used to get rid of deep-rooted mental and psychological disorders. Just as a physical disease arises out of neglect and carelessness towards the body there are subtle and causal diseases that build up in the subtle body and the causal body through carelessness in the way we feel, think, react and interact with life. These subtle ailments manifest indirectly as fears, anxiety, neurosis, psychosis, depression, anger and frustration etc. When 


\section{Journal of Natural \& Ayurvedic Medicine}

these emotions arise they not only affect the conscious plane but even the deeper levels of mind and body. As these are intangible and out of reach, other healing practices are unable to deal with them [9].

Through tattwa shuddhi, the energy which is locked up in matter is released and transformed. It is a dynamic form of meditation and self-reflection. In this practice, you first create a mental and psychic awareness of the five elements and their respective yantras, or geometrical shapes, in the body. You witness the process of one element emerging from another and thus delve deeper and deeper into the subtler layers of existence. After discovering the universal or cosmic energy within, that force is used to dispel inner imbalances. After this transformation, you recreate the elements in the physical body in the reverse order. The practice then culminates in a vision of the dormant cosmic energy. There are several yogic practices designed to increase the flow of prana but Tattwa Shuddhi allows for both increase and transformation of prana.

It is important to understand that through inner concentration on tattwa yantras or geometrical shapes of the elements, we are not only heightening the level of prana but also directly influencing the energy centres in the body called chakras and regulating the anabolic, metabolic and catabolic rates which are so vital for the sound functioning of the body. Also it is said, absorbing the mind in the Earth element induces steadiness of body \& mind; in the Water element-destroys pain and suffering; in Fire - eliminates fear of death; in the Air element - enables astral travel and in the Ether element it paves the way to liberation. In Tattwa Shuddhi we are influencing the physical and pranic sheath by controlling the breath and increasing pranic supply; the mental sheath is influenced by concentration, and the intellectual sheath is awakened by concentration on the tattwa yantras. The influence on these 4 , leads to an experience in the bliss sheath. It is also a good preparation for healing others.

Tattwa Shuddhi is a very subtle but extremely rewarding practice which takes about an hour during which the practitioner is required to sit in a steady position without allowing his mind to be distracted or externalised. Hence it can only be undertaken by individuals who are used to or have some experience of meditation.

\section{Tattwa Yantras (Figure 1)}

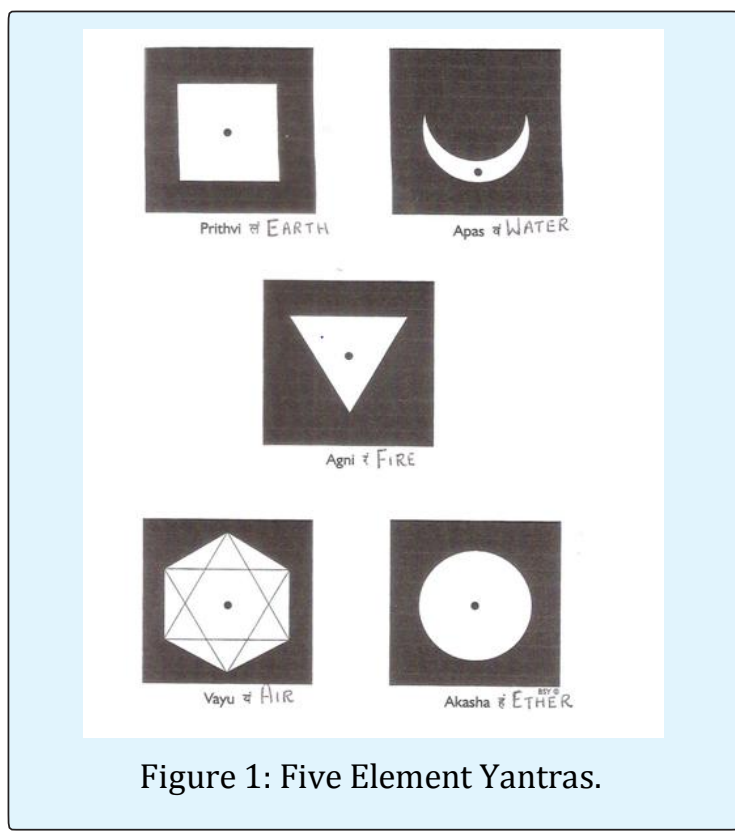

\section{Prana Vidya - As an Art \& Science of Healing Oneself and Others}

Prana $=$ Vital energy + Vidya $=$ Knowledge; Prana Vidya $=$ Knowledge of the life force/ Realisation of the life force. The process whereby the latent energy force or prana in the body is accessed and channelled is called Prana Vidya.

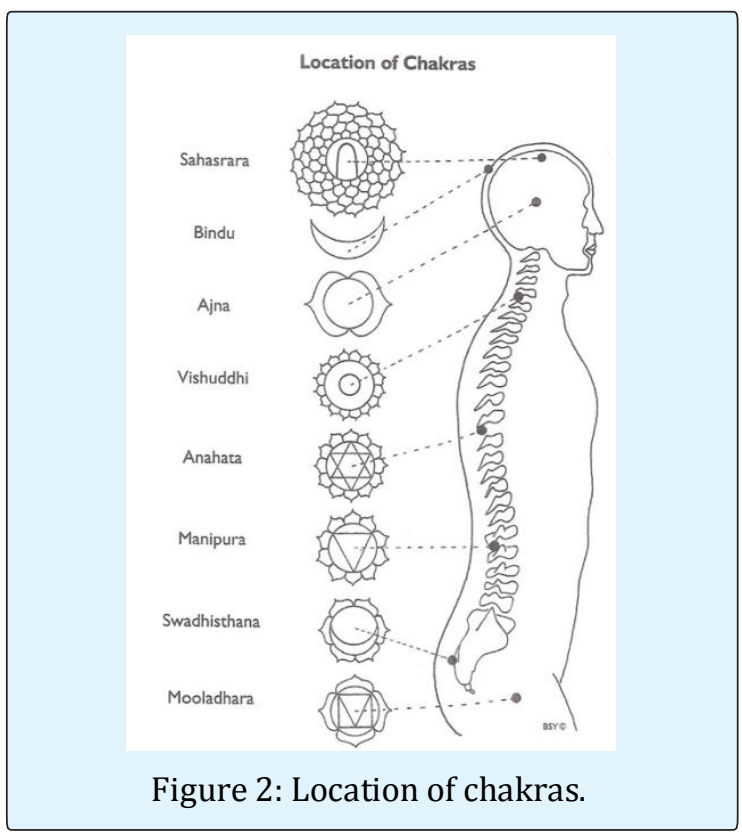




\section{Journal of Natural \& Ayurvedic Medicine}

References to Prana Vidya can be found in the Vedic texts dating back to $500 \mathrm{BC}$ and in later works. But there was no guidance or description provided. It was left to the Guru to pass on the knowledge directly to a deserving disciple. The aim of Pran Vidya is to release the dormant energy force from the body, just as scientists can release nuclear energy from gross matter. Tantric tradition involved awakening energy using the scheme of chakras or energy plexuses and energy channels (called nadis) in the body (Figure 2).

For pranic healing practices to be effective, it is necessary to have awakened the vision of prana shakti the dormant energy force. Charging one's own body or that of another with prana should only take place once the healer or practitioner has experienced genuine pranic awakening. Healing can only happen through the pranic body. Just as voltage of electricity can be increased, the store of prana in the body can be increased. Using intense concentration, one-pointed awareness and visualisation, psychic energy is circulated through specific pranic channels in the body in such a way that this generates vast amount of pranic energy.

In fact Prana Vidya progressively develops awareness and control over the field of prana to such an extent that it brings about an awakening of that great potential that lies dormant within the depths of one's being. By directing this energy to the weak parts one can destroy all diseases. Prana Vidya is an exceptionally subtle, yet powerful practice that requires patience, intense concentration and refined perception [1-5]. It begins with techniques that awaken prana lying dormant within the pranic body. The generating station for prana is mooladhara chakra, the storage centre is manipura chakra and the distribution centre is ajna chakra. Before concluding the practice, it is important to return the awakened energy back to mooladhara, the original source. The practices for selfhealing are two-fold i) for maintaining or restoring general health and ii) for healing physical injuries or illnesses. In the former, prana is distributed to different parts of the body systematically and then to the whole body. In the latter, prana is consciously directed to the relevant part again and again. For healing others, the first step is self-purification through certain prescribed practices, then awakening prana before transmitting the healing energy to others. This is a much more intricate and potent technique than the one followed in ordinary pranic healing.

\section{Conclusions}

- That there is a fundamental connection between emotional dysfunction and physical illness can no longer be denied.

- Conventional doctors are unable to uncover deeply rooted insecurities and personal traumas of their patients. Science remains inadequate at addressing the impact of heartache, grief, rage or love on the physical body.

- The medical fraternity is recognising that the 'stress factor' is indeed a major contributor to diseases such as heart attacks, high blood pressure, ulcers, obesity and nervous disorders.

- It has brought the medical world face to face with the principle of holistic health and yet it is reluctant to acknowledge any alternative healing practices.

- Since majority of physical illnesses result from an overload of mental, emotional and psychological crises, therefore any healing should precede an understanding of the whole person, not just the disease. The human body is a whole entity and should be treated in entirety.

- Health is about the environment you live in and mind is the environment of the body. All psycho-somatic problems emerge from the wrong use of the mind. The mind is the main vehicle we use for all that we do and yet few, if any know what our mind really is and how to use and care for it. Mind can only be disciplined through our consciousness.

- Consciousness can only be reached by transcending the body, mind and senses. The esoteric yogic practices mentioned above are the quickest route to achieving one- pointed awareness and accessing conditioned consciousness.

\section{References}

1. David F (2013) Yoga \& Ayurveda, Self Healing and Self-Realisation, Motilal Banarsidass Publishers Pvt Ltd, Delhi, India, pp: 360.

2. David F (2000) Ayurveda and the Mind, Motilal Banarsidass Publishers Pvt Ltd, Delhi, India

3. Amit G (2011) Quantum Doctor, Hampton Publishing Co Inc, Charlottesville, USA, pp: 320.

4. Saraswati K (1986) Swami: Yogic Management of Common Diseases, Bihar School of Yoga, Munger, Bihar, India. 


\section{Journal of Natural \& Ayurvedic Medicine}

5. Muktibodhananda (2009) Swami: Swara Yoga, Yoga Publication Trust, Munger, Bihar, India.

6. Saraswati N (2013) Swami: Prana \& Pranayama, Yoga Publication Trust, Munger, Bihar, India.

7. Saraswati N (2013) Swami: Prana Vidya (From the Teachings of Swami Satyananda Saraswati), Yoga Pub lication Trust, Munger, Bihar, India.
8. Saraswati S (1993) Swami: Yoga Nidra, Bihar School of Yoga, Munger, Bihar, India.

9. Satyasangananda S, Shuddhi T (2013) Yoga Publication Trust, Munger, Bihar, India.

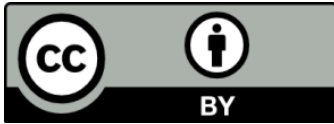

